\title{
Disseminated Listeriosis
}

National Cancer Institute

\section{Source}

National Cancer Institute. Disseminated Listeriosis. NCI Thesaurus. Code C116809.

A bacterial infection by Listeria monocytogenes in two or more non-contiguous sterile body compartments. 